\title{
Mechanical Conditioning for Control of Growth and Quality of Vegetable Transplants
}

\author{
Joyce Griffin Latimer \\ Department of Horticulture, University of Georgia, Georgia Experiment Station, Griffin, GA 30223
}

Physical disturbance of plants or plant parts results in a mechanical stress response from the plant. Mechanical stress applied naturally or under controlled conditions inhibits growth in mass and dimensions of major plant parts. Wind and precipitation are important natural sources of mechanical stress. Under field conditions, cultivated plants experience these natural mechanical stresses plus those caused by irrigation and contact with farm machinery or workers during cultivation. Some horticultural practices, such as staking of trees or potted plants, pinching or pruning stems, deadheading flowers, bagging potted plants, or training branches, are mechanical stresses that affect plant growth. Handling practices in plant science research, such as cross-pollination or tagging of flowers (Frizzell et al., 1960) or repeated attachment of leaf chambers for measurement of water status or photosynthetic rates (Marler and Mickelbart, 1992), also can affect plant growth and physiology.

Grace (1977) extensively studied effects of wind on the growth and physiology of grasses. Jaffe (1973) termed plant response to tactile (touching, rubbing, brushing) mechanical stress "thigmomorphogenesis," whereas plant response to a nontactile (shaking, vibration, wind) treatment was termed "seismomorphogenesis" by Mitchell et al. (1975). However, only recently has plant response to mechanical stress been studied to control plant growth in controlled environments, such as greenhouses and growth chambers (Beyl and Mitchell, 1977b; Hammer et al., 1974).

\section{WHAT IS MECHANICAL CONDITIONING?}

The term "mechanical conditioning" will be used here to refer to the commercial application of natural mechanical stress responses to vegetable transplant production. The following types of treatments will be discussed with respect to mechanical conditioning: Tactile stimulations include touching any part of the plant, rubbing stem sections with the fingers, or brushing the

Received for publication 26 Apr. 1991. The cost of publishing this paper was defrayed in part by the payment of page charges. Under postal regulations, this paper therefore must be hereby marked advertisement solely to indicate this fact. shoots of plants with hands, brooms, paper, or other materials. Nontactile stimulation includes manually shaking potted plants or vibration of the pots or of plants themselves by natural wind or forced aeration. Other treatments, such as a forceful water spray or manually shaking the stem of the plant, combine tactile and nontactile stimulation. Biddington (1986) reviewed the effects of mechanical stress on plant growth and development. This article reviews research results pertinent to use of mechanical stress as a means of conditioning and controlling the growth of vegetable transplants under greenhouse conditions.

\section{WHY DO WE NEED MECHANICAL CONDITIONING?}

Height of bedding plants has been regulated commercially with plant growth retardants such as daminozide (B-Nine, Alar). Treated plants are shorter, sturdier, and darker green and thus more attractive than untreated plants. In 1989, the daminozide label was changed to exclude its use on all food crop plants in the United States, making growth control of vegetable transplants much more challenging. Although reductions in water and nutrient availability may reduce plant growth in controlled environments, these practices may be deleterious to long-term plant growth, development, and productivity (Rubatzky, 1986). The potential for mass application of mechanical conditioning to control growth of vegetable species is excellent because the treatment generally is noninjurious, adaptable to production schedules, and has few longlasting effects on plant development. In fact, treated plants usually resume normal growth 2 to 3 days after treatment ceases (Jaffe, 1973; Mitchell et al., 1975; Neel and Harris, 1972).

\section{MORPHOLOGICAL AND PHYSIOLOGICAL RESPONSES}

\section{Species and cultivar response}

Plant species differ in their responses to mechanical conditioning and to the type of treatment imposed. For example, stem elongation of young barley ( Hordeum vulgare L.), wild hop (Bryonia dioica Jacq.), cucumber ( Cucumis sativa L.), kidney bean (Phaseolus vulgaris L.), and castor bean ( Ricinus communis L.) was significantly re- tarded by rubbing for 10 set daily (Jaffe, 1973). However, rubbing did not affect stem elongation of pumpkin ( Cucurbita pepo L.), pea ( Pisum sativum L.), or wheat ( Triticum aestivum L.). Steucek and Gordon (1975) demonstrated that shaking reduced the growth of a lodging-resistant cultivar of winter wheat but had no influence on that of a lodgingsensitive cultivar. Eggplant ( Solanum melongena L.) and soybean [ Glycine max (L.) Merr.] were responsive to rubbing or shaking, but eggplant was less responsive to wind than was soybean, presumably due to differences in growth habit (Latimer et al., 1986). Although shoot dry weight and leaf area of cauliflower ( Brassica oleracea L.), lettuce ( Lactuca sativa L.), and celery ( $A p$ ium graveolens L.) seedlings were reduced by brushing, the species differed in which plant parts showed the greatest response to treatment (Biddington and Dearman, 1985a). Petiole elongation was most reduced for cauliflower and celery, whereas leaf elongation was most reduced for lettuce. These responses related to differences in natural growth habit of the individual species.

The degree of growth retardation of transplants of four Japanese cucumber cultivars in response to brushing corresponded to the cultivar's normal vigor and growth habit Latimer et al., 1991). Cucumber cultivars with naturally short internodes exhibited less growth reduction than did cultivars with typically longer internodes relative to their respective untreated controls. Four tomato ( Lycopersicon esculentum Mill.) cultivars differing in internode length and vigor showed similar responses; however, hybrids between these cultivars responded in a manner similar to the maternal parent (Johjima et al., 1992). However, four cultivars of chrysanthemum [D endranthema grandiflorum (Ramat.) Kitamura] responded similarly relative to their respective untreated controls, to an automated mechanical stress treatment (Beyl and Mitchell, 1977a).

In addition to species and cultivar differences in growth response to mechanical stress, there also are differences in the degree of damage caused by the treatments. Eggplant seedlings are very easily damaged by stemrubbing treatments (Latimer et al., 1986). Cabbage and broccoli ( Brassica oleraceae L.) are more easily damaged by brushing than is tomato or pepper (Capsicum annuum L.) (Latimer, 1991). However, pepper exhibited more damage than did tomato under the same treatment regime. Differences in 
leaf morphology may account for differences in damage between the species. However, cultivars also differ: 'Dantobi-yohzu' tomato incurred extensive leaf damage during the first week of brushing, whereas six other lines incurred none (Johjima et al., 1992).

\section{Plant responsivity}

The greatest reductions in growth occur in young tissue or tissue directly contacted by the treatment (Mitchell et al., 1975; Turgeon and Webb, 1971). Therefore, mechanical conditioning preferentially reduces stem elongation and leaf expansion, resulting in more compact plants. Younger plants suffer more physical damage, indicating that time of initiating treatment also may affect plant response to the stress Latimer, 1991). However, most vegetable transplants are grown in multicell flats and, to prevent unruly tangling of plants in the flat, brushing must be initiated before plants become undesirably tall. Damage possibly will occur only if there is physical contact with developing tissue, as in brushing. The duration of a brushing treatment also affects the amount of damage incurred (Biddington and Dearman, 1988).

The duration and time of application of mechanical conditioning treatments also may affect the amount of growth reduction. Greater growth inhibition of 'Supersonic' tomato occurred when plants were shaken twice daily for $30 \mathrm{sec}$ than with a daily 60 -sec treatment (Mitchell et al., 1975), but shaking-induced growth reductions of 'Rutgers' tomato seedlings were independent of the time of day treatment was applied (Heuchert and Mitchell, 1983). Inhibition of chrysanthemum stem elongation in response to a single shaking treatment was greatest when the treatment was applied in the morning (Beyl and Mitchell, 1977a). However, one 4-min treatment in the morning resulted in the same growth reduction as four 1-min treatments applied throughout the day, suggesting that the frequency of treatment is less important than the total dosage applied throughout the day. However, Piszczek and Jerzy (1987) found that stem elongation of tomato transplants was reduced more effectively by small doses (5 sec) of shaking stress applied frequently (six times daily) than by a larger dose applied once daily $(60 \mathrm{sec})$ or once every 3rd day $(90 \mathrm{sec})$. Research on mechanical conditioning of vegetable transplants has typically used a minimum of $1.5 \mathrm{~min}$ of brushing applied once (Biddington and Dearman, 1985a) or twice (Latimer, 1990; Latimer et al., 1991) daily.

With respect to commercial production, the more frequent the application and the longer the duration of a mechanical conditioning treatment of vegetable transplants, the greater the growth reduction expected. However, if a single daily treatment is applied, it often is advisable to apply it during the morning hours. Although $\mathrm{CO}_{2}$ uptake resumed within $60 \mathrm{~min}$ after shaking, photosynthetic rates of soybean were reduced for almost $5 \mathrm{~h}$, primarily due to increased stomatal resistance (Pappas and Mitchell, 1985a). Therefore, morning treatments may have longer lasting effects on growth. This responsiveness to application dose makes mechanical conditioning a more flexible treatment than chemical growth regulation.

\section{Seasonality of response}

Seasonal variation in environmental conditions also can affect plant response to mechanical conditioning. Growth of tomato is reduced more by shaking during the winter than during the summer (Heuchert and Mitchell, 1983; Piszczek and Jerzy, 1987), and pea was more responsive during winter than during spring or fall (Akers and Mitchell, 1984). In general, plant response to mechanical conditioning is greater under moderate temperatures and low photon flux levels than under higher levels.

Kidney bean was less responsive. to rubbing when night temperatures were $<16 \mathrm{C}$ rather than above and showed maximal response, compared with untreated controls, at a constant 24C (Hunt and Jaffe, 1980). In preliminary growth-chamber experiments, tomato seedlings grown at high (32C day/ $28 \mathrm{C}$ night) temperatures were less responsive to shaking than plants grown at moderate (27C day/23C night) temperatures (Heuchert and Mitchell, 1983).

Effects of light on plant response to mechanical treatments have been more clearly defined. Stem elongation by tomato seedlings grown under reduced sunlight during the summer exhibited greater response to shaking at low (17\% of full sun) light levels, while leaf area was affected only at higher (44\% of full sun) light levels (Heuchert and Mitchell, 1983). Similar response was obtained in soybean (Pappas and Mitchell, 1985b). Growth chamber studies with soybean confirmed a light-sensitivity response for stem elongation and leaf expansion (Jones et al., 1990). Heuchert and Mitchell (1983) found that equivalent shaking treatments reduced leaf area $34 \%$ during winter but only $19 \%$ during summer, although, through the use of shadecloth during the summer experiment, the total solar energy received during the two experiments was about the same, suggesting undefined interactions with other environmental conditions. Generally, under conditions of low, limiting light, vegetable seedling response to mechanical conditioning likely would improve control of plant height with less effect on leaf growth.

\section{Other morphological responses}

Depending on species, other morphological responses may include increased or decreased stem thickness. However, in either case, mechanical conditioning enhances stem strength and plant resistance to damage during subsequent handling. Kidney bean subjected to stem rubbing or wind exhibited reduced elongation but increased radial enlargement of the stems (Biro and Jaffe, 1984). Rubbed bean stems also were stronger, i.e., had a higher modulus of elasticity, than untreated stems (Jaffe et al., 1984). However, shaking tomato plants resulted in shorter but thinner stems that also were stronger than stems of unshaken plants (Heuchert et al.,
1983). Compared with untreated plants, there was much less stem breakage of brushed cucumber transplants during manual planting to the field (Latimer et al., 1991). These results suggest that mechanical stress could be valuable in preparing plants for the rigors of shipping and field planting.

Pretreatment of transplants with mechanical stress caused a slight increase in stem pithiness of celery under well-watered conditions (Pressman et al., 1984), as well as of tomato (Pressman et al., 1983). Pithiness is a disorder, generally induced by severe drought, that results in a "hollow" or pithy stem (Aloni and Pressman, 1981). Although mechanical conditioning induced some pithiness, it significantly improved plant resistance to more severe, drought-induced stem pithiness for celery and tomato.

Mechanically conditioned plants frequently appear darker green than the controls. Specific chlorophyll content (chlorophyll content per unit dry weight of tissue) increased in shaken tomato (Mitchell et al., 1975), brushed lettuce and celery (Biddington and Dearman, 1985a), and rubbed or shaken eggplant (Latimer and Mitchell, 1988). Specific leaf weight (SLW, leaf dry weight : leaf area), an estimate of leaf density, also increased in tomato (Heuchert and Mitchell, 1983), eggplant and soybean (Latimer et al., 1986), pea (Akers and Mitchell, 1984), soybean (Jones et al., 1990), and in lettuce, celery, and cauliflower (Biddington and Dearman, 1985a) in response to various mechanical conditioning treatments. Increased SLW and chlorophyll content may enhance photosynthetic rate (Nobel and Hartsock, 1981). Because early stages of leaf development influence SLW (Nobel and Hartsock, 1981), mechanical conditioning of greenhouse-grown seedlings or transplants may improve their adaptation to field conditions, in part by increasing SLW Latimer et al., 1986).

Mechanical conditioning generally reduces root growth less than shoot growth, resulting in increased root : shoot ratios in some species, including lettuce (Biddington and Dearman, 1985a), broccoli (Latimer, 1990), cucumber (one of four cultivars) (Latimer et al., 1991), and in three of seven lines of tomato (Johjima et al., 1992). Increases in root : shoot dry weight ratios have been associated with improved field establishment under drought conditions (Watts et al., 1981). Brushing reduced root growth of lettuce, cauliflower, and celery (Biddington and Dearman, 1985a), broccoli (Latimer, 1990), and garden bean (Huberman and Jaffe, 1981), but not of Cucurbita melopepo L. (Turgeon and Webb, 1971), pea (Akers and Mitchell, 1984), or sunflower (Helianthus annuus L.) (Beyl and Mitchell, 1983).

There is limited evidence that mechanical conditioning influences nutrient uptake. Continuous shaking of tall fescue (Festuca arundinacea Schreb.) resulted in greater accumulation of $\mathrm{N}, \mathrm{P}$, and $\mathrm{K}$ in leaves, especially when the plants were grown under conditions of low soil-P levels (Grace et al., 1982). These results may have been related 
to higher transpiration rates of the shaken plants, but shaking reduced growth of plants grown with sufficient $\mathrm{P}$ more than that of plants grown under limited P. Brushing did not affect the uptake of $\mathrm{N}, \mathrm{P}, \mathrm{Ca}$, or $\mathrm{Mg}$ by tomato transplants grown in nutrient solution (Adler and Wilcox, 1987a). However, concomitant with reductions in plant growth, the concentration of $\mathrm{P}$ in tomato shoots was increased, while that of $\mathrm{N}$ was unaffected and that of $\mathrm{K}$ was reduced.

\section{Stress tolerance and field establishment}

During field establishment, transplants generally are subjected to drought and/or temperature stresses. Mechanical conditioning can improve transplant tolerance of stress conditions. Shaking or rubbing increased leaf diffusive resistance and decreased transpiration of tomato (Mitchell et al., 1977), and shaking produced the same responses in soybean (Pappas and Mitchell, 1985a). The rate of water loss from detached kidney bean leaves was reduced by brushing the source plant (Suge, 1980). Also, all bean plants pretreated by brushing before extended water restriction (22 days) survived upon rewatering. No untreated control plants survived the drought stress, although soil moisture content was the same in pots of both treatments (Suge, 1980). In a similar study, young kidney bean plants rubbed for 7 days before imposition of drought stress did not wilt as severely as undisturbed control plants, were more able to recover than were controls after 4 days of water restriction, and resumed normal growth immediately upon rewatering (Jaffe and Biro, 1979). Under environmental stress, a conditioned plant can recover water balance (i.e., resume normal transpiration without experiencing a water deficit) faster than an unconditioned plant (McKee, 1981).

However, Biddington and Dearman (1985b) found that very young (13 or 12 days from seeding), brushed cauliflower or lettuce seedlings exhibited less recovery than did untreated plants when subsequently exposed to "relatively extreme" drought stress. Relative to their respective untreated control plants, transpiration rate per unit leaf area increased in all brushed seedlings. In similar studies, brushing reduced the freezing resistance of 21-day-old cauliflower seedlings subjected to - 3C for $24 \mathrm{~h}$ but had no effect on that of lettuce (Biddington and Dearman, 1988). Since the authors also found that smaller plants were less resistant to freezing damage than were larger plants, their results may not be applicable to plants of the age or size normally considered ready to transplant to the field.

Jaffe and Biro (1979) found that rubbed kidney bean, soybean, maize (Zea mays L.), and mung bean (Vigna radiata L.) plants exhibited increased resistance to a freezing stress (- 13C for $5 \mathrm{~min}$ ). The amount of protection varied with the degree of plant-growth response to rubbing. For example, the greatest reduction in stem elongation and the greatest frost resistance occurred for soybean, but little growth response and only mild freeze protection occurred for mung bean. How- ever, daily brushing of tomato transplants for 15 days did not improve chilling resistance of plants subjected to 2.X for $72 \mathrm{~h}$ (Pardossi et al., 1988). There have been no systematic studies of the effect of mechanical conditioning on stress tolerance of vegetable crops. Reviewing previous results, it is possible that some species conditioned with mechanical stress, perhaps the warm-season vegetable crops in particular, will be more tolerant of drought and chilling stresses than are unconditioned plants.

In addition to improving tolerance to drought and freezing stresses, mechanical conditioning has improved plant establishment in the field. Liptay (1985) reported that tomato seedlings vibrated by an under-thebench air source established rapidly. There were no differences in plant dry weight,after 3 weeks in the field, although the initial dry weight of treated transplants was $34 \%$ less than that of untreated plants. Field establishment of brushed broccoli transplants, measured by shoot dry weight gain during the first 2 weeks in the field, was significantly better than that of untreated transplants in two of three tests (Latimer, 1990). These responses have not been fully characterized but may be due to improvements in stress tolerance (Jaffe and Biro, 1979; Suge, 1980), increased root : shoot dry weight ratio (Biddington and Dearman, 1985a; Latimer, 1990), improved P uptake by treated shoots (Adler and Wilcox, 1987a; Grace et al., 1982), or the "accelerated" growth rate identified in plants relieved of mechanical stress treatment (Jaffe, 1973; Mitchell et al., 1975; Neel and Harris, 1972). The process of "crossadaptation," i.e., preconditioning a plant with one type of physiological stress to make the plant more tolerant of other stresses, also may play a role in improved field establishment of treated transplants (Boussiba et al., 1975; Krizek, 1987).

\section{Long-term effects on yield}

Mechanical conditioning usually affects plant growth only during the period of treatment, plus about a 3-day recovery period, which makes it a desirable growth control treatment for vegetable transplants. However, there have been reports of long-term treatment effects on yield. Under greenhouse conditions, daily shaking during vegetative and reproductive growth phases decreased tuber weight of potato (Solanum tuberosum L.) without affecting the number of tubers produced (Akers and Mitchell, 1985). Similarly, daily shaking of 'Patio' tomato during vegetative and reproductive development delayed anthesis but improved fruit set (Akers and Mitchell, 1985). Twice-daily shaking of tomato plants during fruit production in the greenhouse reduced yields $18 \%$, but shaking on alternate days did not affect yield (Buitelaar, 1989). Brushing potted soybean during various periods of vegetative and/or reproductive development did not affect seed yield (Umezaki and Matsumoto, 1990).

Few long-term effects are expected from mechanical conditioning of transplants since reproductive tissues generally are not treated.
Brushing lettuce seedlings only during transplant production reduced the size and improved the handling characteristics of the transplants (Wurr et al., 1986). However, brushing did not affect lettuce head weight at maturity in the field. Brushing or wind treatment of broccoli transplants during their production in the greenhouse had no effect on subsequent head weight during field production Latimer, 1990). Brushing increased subsequent root yield from sugar beet (Beta vulgaris L.) transplants, but excess growth inhibition of transplants caused a corresponding yield decrease (Takaki et al., 1977). Brushing tomato transplants before setting them in a cold (9C) greenhouse reduced early, but not total, yield (Pardossi et al., 1988). In contrast, brushing tomato transplants subsequently set in a warm greenhouse had no effect on early or total yield (Johjima et al., 1992).

These differences in yield response to mechanical stress again may be due to differences in cultivars or species. However, the lack of detail in many published reports prevents determination of the developmental state of the transplants at the time brushing ceased. Brushing can physically damage reproductive structures such as tomato flowers (Johjima et al., 1992) that may be present during the latter stages of treatment. Physical damage to flowers could contribute directly to decreased early yields such as those reported by Pardossi et al. (1988). However, brushed 'Ritsurin' cucumber had comparably reduced yields over the entire harvest period, whereas the yield of three other cultivars was unaffected by transplant brushing Latimer et al., 1991). Both the physical and physiological long-term effects of mechanical conditioning must be more adequately defined.

\section{Disease incidence}

Another potential problem that must be addressed is the effect of mechanical conditioning on disease incidence and spread. Mechanical procedures such as clipping, pruning, or taking cuttings may promote disease spread by dissemination of pathogens. Although we have observed no disease incidence in our studies with brushing, it would be prudent to assume that brushing also can spread pathogens. Therefore, we have recommended that any diseased plants be culled before brushing and that plants be treated only when the foliage is dry (Latimer, 1991).

Brushed plants have been shown to be more susceptible to infection than are untreated plants. When tomato transplants previously inoculated with Fusarium oxysporum [Schlechtend.: Fr. f. sp. lycopersici (Sacc.) Snyder \& Hans] were brushed for 14 days, incubation time for the disease was reduced and symptom expression was more severe than for plants not subjected to brushing (Shawish and Baker, 1982). Flax (Linum usitatissimum L.) and pea seedlings exhibited similar responses to their respective $\mathrm{Fu}$ surium pathogens. In addition, in a test using a limited sample size, cuttings taken from tomato plants that had been brushed for 5 
days were inoculated, rooted, and transplanted into pots. When evaluated 50 days later, cuttings taken from brushed plants had more severe symptom expression than those from unbrushed plants.

Additional research is necessary to determine how mechanical conditioning would predispose seedlings to infection by Fusarium wilt pathogens, the reason for the persistence of this predisposition, and the susceptibility of treated plants to other plant pathogens. Nontactile forms of mechanical conditioning, like shaking or exposure to wind, probably will have little effect on disease spread. However, the effect of the treatments on predisposition to disease may be the same as for brushing. Mechanical conditioning affects the hormone balance in plants, particularly with respect to root-produced hormones (Beyl and Mitchell, 1983; Suge, 1978), which also may affect plant susceptibility to disease. The longevity of these hormone responses and their impact on disease predisposition is unknown.

\section{Mechanism of response}

The generality of plant response to mechanical stress in the absence of gross physical damage has prompted many studies on the physiological effects of these treatments on plants. However, the mechanism of the mechanical stress response still is unclear. Recently discovered "touch-induced genes" in Arabidopsis have added a new dimension to mechanical stress research (Braam and Davis, 1990). Three of five genes identified encode calmodulin and calmodulin-related proteins. Jones and Mitchell (1989) found that calmodulin antagonists partially negated the growth inhibition of rubbed soybean hypocotyls, which supports a role for calmodulin and $\mathrm{Ca}$ in the mechanical stress response. The interaction of these systems and their effects on whole-plant growth and physiology presently are unknown.

On a whole-plant scale, the role of plant growth regulators in response to mechanical stress is unclear. Ethylene has been implicated in many mechanical stress responses (Biddington, 1986). Responses to mechanical stress may involve an interaction between auxin and ethylene (Erner and Jaffe, 1982; Mitchell, 1977). However, studies involving the application of ethylene or inhibitors of its production prove that ethylene does not account for all plant responses to mechanical stress (Biro and Jaffe, 1984; Takahashi and Jaffe, 1984; Takahashi and Suge, 1980). In brushed cauliflower seedlings, ethylene did not appear to be responsible for any aspects of growth retardation (Biddington and Dearman, 1986). Ethylene production actually may be a result of the regulation of touch-induced gene expression rather than an inducer of gene expression (Braam and Davis, 1990).

Mechanical stress also affects the production of growth promoters and inhibitors. Reductions in gibberellin-like promoters, demonstrated for shaken sunflower (Beyl and Mitchell, 1983) and brushed bean (Suge, 1978), may be responsible for reductions in stem elongation and leaf expansion. Rubbing or shaking inhibited polar auxin transport in pea stems (Mitchell, 1977). Abscisic acid or other inhibitors increased in rubbed bean (Emer and Jaffe, 1982), brushed rice (Oryza sativa L.) (Jeong and Ota, 1980), and shaken or rubbed sunflower (Beyl and Mitchell, 1983), but was unchanged in eggplant by 3 days of shaking (Latimer and Mitchell, 1988) or by brushing in lettuce or cauliflower seedlings (Biddington and Dearman, 1988). Increases in abscisic acid may enhance drought stress tolerance (Jaffe and Biro, 1979; Suge, 1980) and freezing resistance (Jaffe and Biro, 1979). Determining the role of plant hormones in mechanical conditioning may provide information on the mechanism of plant response between gene induction and regulation and plant growth and development.

\section{RELATIONSHIP TO OTHER} GROWTH-CONTROL METHODS

Mechanical conditioning results in plants that appear very similar to those treated with growth retardants like daminozide or chlormequat (Adler and Wilcox, 1987b; Beyl and Mitchell, 1977a; Biddington and Dearman, 1987b). Although chemical growth retardants are readily available for production of greenhouse-grown ornamental bedding plants, none is labeled for use on vegetable species. Growers are now limited to nonchemical means of growth control for vegetable transplants. Drought stress or water restriction also reduces transplant growth and, if severe, may affect final crop yield. Biddington and Dearman (1987a) established that lettuce and cauliflower seedlings grown under nutrient or drought stress were at least as responsive to brushing as were nonstressed seedlings, and the effects of combined treatments on lettuce seedling growth were multiplicative rather than additive. Sugar beet transplant growers in Japan use a combination of brushing and drought stress to control growth during plant culture (Fletcher, 1984). This combination of mechanical conditioning with drought may reduce the severity of drought required to achieve adequate growth control.

Bedding plant growth also can be controlled by manipulation of day and night temperature to maintain a predetermined temperature difference (DIF; Karlsson et al., 1989). Crops such as squash are unresponsive to DIF, whereas tomato, bean, watermelon [Citrullus lanatus (Thunb.) Matsum. \& Nakai], and sweet corn (Zea mays L. var. rugosa Bonaf.) are greatly affected (Heins and Erwin, 1990). Bedding plant growers in Michigan using DIF found that the overall quality of their vegetable transplants was not as good as in previous years when daminozide (Alar) was applied, and they expressed the desire to have additional options available for growth control and conditioning (Ferretti, 1990). Combining mechanical conditioning with DIF may provide the improved green pigmentation and sturdy stems lacking in tomato transplants grown with DIF.

Nutrient restriction frequently is used to control plant height but can cause long-term reduction in plant growth or crop yield (Weston and Zandstra, 1986). Providing optimal nutrient balance by pretransplanting nutritional conditioning (PNC) improved the growth and quality of tomato transplants (Melton and Dufault, 1991). In muskmelon transplants, PNC reduced transplant shock in the field and improved final fruit yield and quality (Dufault, 1986). Although growth control is adequate with PNC, the addition of mechanical conditioning, especially if plants must be held back due to poor planting conditions, may provide some additional benefits in transplant handling and establishment.

Manipulation of light quality or duration also may improve transplant quality while maintaining growth control. Supplementary fluorescent light improved the quality of lettuce transplants (Wurr et al., 1986) and outdoor adaptation of eggplant (Latimer and Mitchell, 1987). Brief, daily exposure to a high red : far-red light ratio was very effective in reducing stem elongation of bell pepper, presumably by affecting phytochrome photoequilibrium (Decoteau et al., 1990). Manipulation of the red : far-red ratio through the use of copper sulfate filters in the greenhouse also reduced bedding plant height (Benson and Kelly, 1990).

Many of the nonchemical growth-control methods being studied result in similar changes in growth patterns, thereby providing new opportunities to discern the mechanisms behind these responses. There also are many opportunities to combine methods for various sytems and crops. Cost effectiveness of the various methods and of some combinations should be analyzed once commercially applicable systems are designed.

\section{COMMERCIAL APPLICATION OF MECHANICAL CONDITIONING}

Methods of applying mechanical stress vary with individual researchers; some are more applicable to commercial use than others. Rubbing individual stems (Jaffe, 1973) or shaking small groups of individual pots (Mitchell et al., 1975) clearly is too labor intensive for commercial application. However, Beyl and Mitchell (1977b) designed an automated, mechanical oscillatory shaking (AMOS) device for applying a combined rubbing and shaking treatment to groups of potted chrysanthemums on a greenhouse bench. AMOS is fully adjustable for plant height and applies a uniform mass stress treatment, but the device is cumbersome, not portable, and unsuitable for certain growth habits (Beyl and Mitchell, 1977b). AMOS would require much redesign to be suitable for the high-density production of vegetable transplants.

Treatments such as manually brushing with a small broom are used commercially in Japan (Takaki et al., 1977), where transplant production units generally are small. Other brushing materials used in research include: typing paper (Biddington and Dearman, 1985a), cardboard Latimer, 1990), vinyl net 
covering (as a static counterforce) (Beyl and Mitchell, 1977a; Hiraki and Ota, 1975), a dusting brush (Hiraki and Ota, 1975), suspended aluminum bars (Nakaseko, 1988), steel bars suspended in a cloth sling Latimer et al., 1991), or a wooden pole Latimer, 1991). Materials to which leaves adhere, such as polyvinyl chloride or painted pipes, or materials that tangle with certain leaf types such as a draftsman's brush with tomato, cause excessive damage and should be avoided. Some treatments may be adaptable for commercial application of mechanical conditioning to large numbers of uniform plants. Beyl and Mitchell (1977b) suggested the use of "mechanical fingers" drawn across crop canopies or vibration of entire benches as being commercially feasible. A system for vibration of movable metal benches that are commonly used in greenhouses would be simple and cost-effective.

Other effective methods of applying mechanical stress include a daily 10 -sec water spray (Wheeler and Salisbury, 1979), vibration via aeration (wind) from below the bench (Liptay, 1985), or wind stress from oscillating (Adler and Wilcox, 1987b) or unidirectional fans (Adler and Wilcox, 1987b; Beyl and Mitchell, 1977b; Latimer, 1990). Although water spray would be a convenient application method, especially by pressurizing the boom sprayers commonly used in greenhouses, irrigation timing may not correspond with the need for growth control. Wind stress causes many changes in the microenvironment of plants (Grace and Russell, 1982), and may cause desiccation of plant material (Latimer, 1990). Use of a humidified airstream applied intermittently was suggested by Beyl and Mitchell (1977b) as being feasible as part of a boom irrigation system.

Methods of rapid and uniform mass application of a mechanical conditioning treatment that do not require manual handling of plant material will be more flexible for greenhouse operators. Uniform application of a brushing treatment across cucumber plants differing in height was very difficult (Latimer et al., 1991) and would not be feasible for very small plants that differed significantly in height. Conversely, brushing tends to produce more height uniformity within groups of plants, provided the initial differences were not so great as to permit excessive damage to the tallest plants.

\section{SUMMARY}

Mechanical conditioning has excellent potential for control of growth and quality of vegetable transplants. The treatment generally is noninjurious, flexible, and has few long-lasting effects on plant growth. Mechanical conditioning improves plant appearance by increasing specific chlorophyll content, thereby increasing the degree of greenness, and by reducing stem elongation, thereby contributing to a more sturdy plant. Mechanical conditioning improves plant performance by increasing stem and petiole strength, thereby decreasing plant breakage and loss during shipping and planting; it also improves stress tolerance and field establishment of some crops. Although some negative effects on yield have been identified, pretreatment of transplants generally does not affect final crop yield.

Methods of treatment application, differences in species and cultivar response, and sensitivity to damage must be further defined to fully recommend mechanical conditioning as a means of nonchemical growth control of vegetable transplants. The interaction of mechanical conditioning with other cultural and management practices, such as integrated pest management and fertilization, also must be determined for various cropping systems. There are many opportunities to study different combinations of the nonchemical growth-control methods available to growers. Mechanical conditioning has good potential as a flexible addition to the growthcontrol program for many species and production systems.

\section{Literature Cited}

Adler, P.R. and G.E. Wilcox. 1987a. Influence of thigmic stress or chlormequat chloride on tomato morphology and elemental uptake. J. Plant Nutr. 10:831-840.

Adler, P.R. and G.E. Wilcox. 1987b Salt stress, mechanical stress, or chlormequat chloride effects on morphology and growth recovery of hydroponic tomato transplants. J. Amer. Soc. Hort. Sci. 112:22-25.

Akers, S.W. and C.A. Mitchell. 1984. Seismic stress effects on vegetative and reproductive development of 'Alaska' pea. Can. J. Bot. 62:2011-2015.

Akers, S.W. and C.A. Mithcell. 1985. Seismic stress effects on reproductive structures of tomato, potato, and marigold. HortScience 20:684686.

Aloni, B. and E. Pressman. 1981. Stem pithiness in tomato plants: The effect of water stress and the role of abscisic acid. Physiol. Plant. 51:3944.

Benson, J. and J. Kelly. 1990. Effect of copper sulfate filters on growth of bedding plants. HortScience 25:1144. (Abstr.)

Beyl, C.A. and C.A. Mitchell. 1977a. Characterization of mechanical stress dwarfing in chrysanthemum. J. Amer. Soc. Hort. Sci. 102:591594.

Beyl, C.A. and C.A. Mitchell. 1977b. Automated mechanical stress application for height control of greenhouse chrysanthemum. HortScience 12:575-577.

Beyl, C.A. and C.A. Mitchell. 1983. Alteration \&growth, exudation rate, and endogenous hormone profiles in mechanically dwarfed sunflower: J. Amer. Soc. Hort. Sci. 108:257-262.

Biddington, N.L. 1986. The effects of mechanically-induced stress in plants-a review. Plant Growth Regulat. 4:103-123.

Biddington, N.L. and A.S. Dearman. 1985a. The effect of mechanically induced stress on the growth of cauliflower, lettuce and celery seedlings. Ann. Bot. 55:109-119.

Biddington, N.L. and A.S. Dearman. 1985b. The effect of mechanically-induced stress on water loss and drought resistance in lettuce, cauliflower and celery seedlings. Ann. Bot. 56:795802.

Biddington, N.L. and AS. Dearman. 1986. A comparison of the effect of mechanically-in- duced stress, ethephon and silver thiosulphate on the growth of cauliflower seedlings. Plant Growth Regulat. 4:33-41.

Biddington, N.L. and A.S. Dearman. 1987a. The effects of mechanically-induced stress on the growth of water and nutrient deficient lettuce and cauliflower seedlings. Ann. Bot. 59:679683.

Biddington, N.L. and A.S. Dearman. 1987b. The effects of mechanically-induced stress and plant growth regulators on the growth of lettuce, cauliflower and bean (Phaseolus vulgaris L.) plants. Plant Growth Regulat. 5:183-194.

Biddington, N.L. and AS. Dearman. 1988. The effects of mechanically-induced stress and water stress on freezing resistance in lettuce and cauliflower seedlings. J. Hort. Sci. 63:609-614.

Biro, R.I. and M.J. Jaffe. 1984. Thigmomorphogenesis: Ethylene evolution and its role in the changes observed in mechanically perturbed bean plants. Physiol. Plant. 62:289-296.

Boussiba. S.. A. Rikin. and A.E. Richmond. 1975. The role of abscisic acid in cross-adaptation of tobacco plants. Plant Physiol. 56:337-339.

Braam, J. and R.W. Davis. 1990. Rain-, wind-, and touch-induced expression of calmodulin and calmodulin-related genes in Arabidopsis. Cell 60:357-364.

Buitelaar, K.. 1989. Tomatoes. Plant movement can lead to a lower yield (in Dutch). Groenten en Fruit 44(29):31. [Hort. Abstr. 59:7515.1989.]

Decoteau. D.R.. M.J. Kasperbauer. and P.G. Hunt. 1990. 'Bell pepper plant development over mulches of diverse colors. HortScience 25:460462.

Dufault, R.J. 1986. Influence of nutritional conditioning on muskmelon transplant quality and early yield. J. Amer. Soc. Hort. Sci. 111:698703.

Erner, Y. and M.J. Jaffe. 1982. Thigmomorphogenesis: The involvement of auxin and abscisic acid in growth retardation due to mechanical perturbation. Plant \& Cell Physiol. 23:935-941.

Ferretti, P.A. 1990. Growing transplants without Alar. Greenhouse Grower's Plug Guide 8(11):55-56.

Fletcher, B. 1984. Sugar beet growing in Japan. Brit. Sugar Beet Rev. 52(4):8-10.

Frizzell, J.L., L.C. Brown, and B.A. Waddle. 1960. Some effects of handling on the growth and development of cotton. Agron. J. 52:6970

Grace, J. 1977. Plant responses to wind. Academic, London.

Grace, J., C.E.R. Pitcairn, G. Russell, and M. Dixon. 1982. The effects of shaking on the growth and water relations of Festuca arundinacea Schreb. Ann. Bot. 49:207-215.

Grace, J. and G. Russell. 1982. The effect of wind and a reduced supply of water on the growth and water relations of Festuca arundinaceae Schreb. Ann. Bot. 49:217-225.

Hammer, P.A., CA. Mitchell, and T.C. Weiler. 1974. Height control in greenhouse chrysanthemum by mechanical stress. HortScience 9:474475.

Heins, R. and J. Erwin. 1990. Understanding and applying DIF. Greenhouse Grower 8(2):73-76.

Heuchert. J.C. and C.A. Mitchell. 1983. Inhibition of shoot growth in greenhouse-grown tomato by periodic gyratory shaking. J. Amer. Soc. Hort. Sci. 108:795-800.

Heuchert, J.C., J.S. Marks, and C.A. Mitchell. 1983. Strengthening of tomato shoots by gyratorv shaking. J. Amer. Soc. Hort. Sci. 108:801$8 \begin{array}{lll}8 & 0 & 5\end{array}$

Hiraki, Y. and Y. Ota. 1975. The relationship between growth inhibition and ethylene production by mechanical stimulation in Lilium longiflorum. Plant \& Cell Physiol. 16:185-189. 
Huberman, M. and M.J. Jaffe. 1981. Morphological changes of mechanically-perturbed or ethylene treated bean plants. Plant Physiol. 67(Suppl.): 17.

Hunt, E.R., Jr. and M.J. Jaffe. 1980. Thigmomorphogenesis: The interaction of wind and temperature in the field on the growth of Phaseolus vulgaris L. Ann. Bot. 45:665-672.

Jaffe, M.J. 1973. Thigmomorphogenesis: The response of plant growth and development to mechanical stimulation. Planta 114:143-157.

Jaffe, M.J. and R. Biro. 1979. Thigmomorphogenesis: The effect of mechanical perturbation on the growth of plants, with special reference to anatomical changes, the role of ethylene, and interaction with other environmental stresses, p. 25-59. In: H. Mussel1 and R.C. Staples (eds.). Stress physiology in crop plants. Wiley, New York

Jaffe, M.J., F.W. Telewski, and P.W. Cooke. 1984. Thigmomorphogenesis: On the mechanical properties of mechanically perturbed bean plants. Physiol. Plant. 62:73-78.

Jeong, Y.-H. and Y. Ota. 1980. A relationship between growth inhibition and abscisic acid content by mechanical stimulation in rice plant. Jpn. J. Crop Sci. 49:615-616.

Johjima, T., J.G. Latimer, and H. Wakita. 1992. The effect. of mechanical stress on transplant growth and subsequent yield of four cultivars of tomato and their hybrid lines. J. Amer. Soc. Hort. Sci. (In press.)

Jones, R.S. and C.A. Mitchell. 1989. Calcium ion involvement in growth inhibition of mechanically stressed soybean (Glycine mar) seedlings. Physiol. Plant. 76:598-602.

Jones, R.S., L.L. Coe, L. Montgomery, and C.A. Mitchell. 1990. Seismic stress responses of soybean to different photosynthetic photon flux. Ann. Bot. 66:617-622.

Karlsson, M.G., R.D. Heins, J.E. Erwin, R.D. Berghage, W.H. Carlson, and J.A. Biernbaum. 1989. Temperature and photosynthetic photon flux influence chrysanthemum shoot development and flower initiation under short-day conditions. J. Amer. Soc. Hort. Sci. 114:158-163.

Krizek, D.T. 1987. A little stress can help plants cope. Agr. Res. 35:8.

Latimer, J.G. 1990. Drought or mechanical stress affects broccoli transplant growth and establishment but not yield. HortScience 25:1233-1235.

Latimer, J.G. 1991. Brushing can control transplant height. Amer. Veg. Grower 39(4):98, 102103.

Latimer, J.G. and C.A. Mitchell. 1987. W-B radiation and photosynthetic irradiance acclimate eggplant for outdoor exposure. HortScience 22:426-429.

Latimer, J.G. and C.A. Mitchell. 1988. Effects of mechanical stress or abscisic acid on growth, water status and leaf abscisic acid content of eggplant seedlings. Scientia Hort. 36:37-46.
Latimer, J.G., T. Johjima, and K. Harada. 1991 The effect of mechanical stress on transplant growth and subsequent yield of four cultivars of cucumber. Scientia Hort. 47:221-230.

Latimer, J.G., T. Pappas, and CA. Mitchell. 1986. Growth responses of eggplant and soybean seedlings to mechanical stress in greenhouse and outdoor environments. J. Amer. Soc. Hort. Sci. 111:694-698.

Liptay, A. 1985. Reduction of spindliness of tomato transplants grown at high densities. Can. J. Plant Sci. 65: 797-801.

Marler, T.E. and M.V. Mickelbart. 1992. Repeated mechanical stress from leaf cuvette influences leaf gas exchange. HortScience. (In press.)

McKee, J.M.T. 1981. Physiological aspects of transplanting vegetables and other crops. I. Factors which-influence re-establishment. Hort. Abstr. 51:265-272.

Melton, R.R. and R.J. Dufault. 1991. Nitrogen, phosphorus, and potassium fertility regimes affect tomato transplant growth. HortScience 26:141-142.

Mitchell, C.A. 1977. Influence of mechanical stress on auxin stimulated growth of excised pea stem sections. Physiol. Plant. 41:129-134.

Mitchell, C.A., C.J. Severson, J.A. Wott, and P.A. Hammer. 1975. Seismomorphogenic regulation of plant growth. J. Amer. Soc. Hort. Sci. 100:161-165.

Mitchell, C.A., H.C. Dostal, and T.M. Seipel. 1977. Dry weight reduction in mechanicallydwarfed tomato plants. J. Amer. Soc. Hort. Sci. 102:605-608.

Nakaseko, K. 1988. Productivity of a dwarf type soybean induced by mechanical stimulation applied during vegetative stage. Jpn. J. Crop. Sci. 57:782-789.

Neel, P.L. and R.W. Harris. 1972. Tree seedling growth: Effects of shaking. Science 175:918919.

Nobel, P.S. and T.L. Hartsock. 1981. Development of leaf thickness for Plectranthus parviflorus- influence of photosynthetically active radiation. Physiol. Plant. 51:163-166.

Pappas, T. and C.A. Mitchell. 1985a. Influence of seismic stress on photosynthetic productivity, gas exchange, and leaf diffusive resistance of Glycine $\max$ (L.) Merrill cv. Wells II. Plant Physiol. 79:285-289.

Pappas, T, and C.A. Mitchell. 1985b. Effects of seismic stress on the vegetative growth of Glycine $\max$ (L.) Merr. cv. Wells II. Plant Cell \& Environ. 8:143-148.

Pardossi, A., F. Togoni, and S.S. Lovemore. 1988 The effect of different hardening treatments on tomato seedling growth, chilling resistance and crop production in cold greenhouse. Acta Hort. 229:371-379.

Piszczek, P.M. and M. Jerzy. 1987. The response of tomato (Lycopersicon esculentum Mill.) transplants to mechanical stress. Acta Agrobot. 40:5-14

Pressman, E., M. Huberman, B. Aloni, and M.J. Jaffe. 1983. Thigmomorphogenesis: The effect of mechanical perturbation and ethrel on stem pithiness in tomato [Lycopersicon esculentum (Mill.)] plants. Ann. Bot. 52:93-100.

Pressman, E., M. Huberman, B. Aloni, and M.J. Jaffe. 1984. Pithiness in plants: I. The effect of mechanical perturbation and the involvement of ethylene in petiole pithiness in celery. Plant \& Cell Physiol. 25:894-897.

Rubatzky, V. 1986. Safeguard transplants. Amer. Veg. Grower 34:46-48.

Shawish, O. and R. Baker. 1982. Thigmomorphogenesis and predisposition of hosts to $\mathrm{Fu}-$ sarium wilt. Phytopathology 72:63-68.

Steucek, G.L. and L.K. Gordon. 1975. Response of wheat (Triticum aestivum) seedlings to mechanical stress. Bot. Gaz. 136:17-19.

Suge, H. 1978. Growth and gibberellin production in Phaseolus vulgaris as affected by mechanical stress. Plant \& Cell Physiol. 19:1557-1560.

Suge, H. 1980. Dehydration and drought resistance in Phaseolus vulgaris as affected by mechanical stress. Rpt. Inst. Agr. Res. Tohoku Univ. 31:1-10.

Takahashi, H. and M.J. Jaffe. 1984. Thigmomorphogenesis: The relationship of mechanical perturbation to elicitor-like activity and ethylene production. Physiol. Plant. 61:405-411.

Takahashi, H. and H. Suge. 1980. Sex expression in cucumber plants as affected by mechanical stress. Plant \& Cell Physiol. 21:303-310.

Takaki, A., T. Masuda, N. Tsukishima, K. Kagawa, and K. Kurosawa. 1977. The effect of mechanical stimulation on the seedling growth of sugar beets. Proc. Sugar Beet Res. Assn. 19:203-212.

Turgeon, R. and J.A. Webb. 1971. Growth inhibition by mechanical stress. Science 174:961962.

Umezaki, T. and S. Matsumoto. 1990. Studies on internode elongation in soybean plants. Jpn. J. Crop. Sci. 59:34-39.

Watts, S., J.L. Rodriguez, S.E. Evans, and W.J. Davies. 1981. Root and shoot growth of plants treated with abscisic acid. Ann. Bot. 47:595602.

Weston, L.A. and B.H. Zandstra. 1986. Effect of root container size and location of production on growth and yield of tomato transplants. J. Amer. Soc. Hort. Sci. 111:498-501.

Wheeler, R.M. and F.B. Salisbury. 1979. Water spray as a convenient means of imparting mechanical stimulation to plants. HortScience 14:270-271.

Wurr, D.C.E., J.R. Fellows, and P. Hadley. 1986. The influence of supplementary lighting and mechanically-induced stress during plant raising on transplant and maturity characteristics of crisp lettuce. J. Hort. Sci. 61:325-330. 